\title{
English Classroom Learning Engagement Research for Medical College Students
}

\author{
Zeng Xiangfa $^{1, a}$, Zhang Fen ${ }^{2, b^{*}}$ \\ 1English Teaching Department, Chengdu Medical College, Chengdu, Sichuan, China 610500 \\ 2*Corresponding Author, English Teaching Department, Chengdu Medical College, Chengdu, \\ Sichuan, China 610500
}

a1362806408@qq.com, b1006893531@qq.com

Keywords: Classroom learning engagement; Medical students; English proficiency

\begin{abstract}
This study is to explore the current situation and influential factors of medical college students' English class engagement. A total of 1224 medical students from 17 medical majors in one college were surveyed and SPSS21.0 statistical package is used for data analysis. Statistical analysis showed that the overall engagement level of medical students was not high, and the average weekly class engagement number for per 6 periods was $2.84 \pm 2.054$. Students' motivation, learning behavior, English level and teaching methods affect students' class engagement. Teachers can improve medical college students' English class engagement by applying flipped classroom, PBL teaching and games. Medical students also need to establish correct mobile phone culture, enhance learning subjective initiative, and actively participate in teaching activities to improve their comprehensive English proficiency.

As the most widely used language in the world, English is an important tool for international exchanges, science and technology and cultural exchanges. English proficiency plays an important role in students' professional study, international exchange, work. College English is a compulsory public basic course for medical students. In traditional teaching process, teachers "teach" on the platform and students indifferently "listen". It is difficult to form an effective and positive interaction and exchange between teachers and students. And some students show non-participating state behaviorally or psychologically, such as: do not finish homework, do not speak up, or feel tired of learning, etc. College English teaching is an interactive process of teacher-student interaction, and students' class engagement is directly related to the success of teaching activity, and it also directly affects the formation of students' English language ability. Therefore, college English teaching should take students as the center, mobilize the enthusiasm and initiative of students from the reality, and allow more students to better participate in classroom learning ${ }^{[1]}$.

Class engagement refers to the psychological action ways and behavior levels of teachers and students in classroom teaching process, including behavior engagement, cognitive engagement and emotional engagement ${ }^{[2]}$. At present, primary and secondary students' engagement have been the domestic research focus. Xia Lili took the new version of "English" textbook as an example, regarded English learning as "playing an overall game" from the perspective of "overall learning". She provided students with "threshold experience", created "opportunity culture" and established "difficulties theory", thereby enhancing students' engagement in English learning ${ }^{[3]}$. Xu Jinglin studied the engagement of 45 freshmen in a higher vocational college from learning environment and engagement ways ${ }^{[4]}$. Results show that students' participatory status in experiential English learning is overall more positive, and the differences in learning environment have no significant effect on students' English learning engagement. At present, college students, especially medical college students, are less involved in the research. In order to investigate the class engagement of medical students in college English teaching and its influencing factors, the author designed a questionnaire. Software analysis package is applied for analysis. Corresponding teaching suggestions are put forward accordingly in order to improve the engagement of medical students in college English classroom and improve medical students’ English language proficiency.
\end{abstract}




\section{Research subjects and research methods}

Research subjects. Research subjects are all 2017 medical majors in a college, a total of 1224 medical students majoring Applied Psychology, Rehabilitation, Biotechnology, Medical Imaging, Biomedical Engineering, Pediatrics, Clinical Medicine, Health Inspection and Quarantine, Medical Examination Technology, etc. Of the 1224 medical students, 445 are boys, accounting for 37.4\% and 744 are girls, accounting for $62.6 \%$ with an average age of $18.53 \pm 0.782$.

Research methods. Questionnaire was distributed to the subjects. The questionnaire is revised according to the Self-determinative Theory and is based on He Rong Questionnaire ${ }^{[5]}$ with a total of 21 questions. Likert Scale 5 (ie, "totally agree", "agree", "not necessarily", "disagree", "totally disagree" five answers, respectively, as 5,4,3, 2,1 points.) is adopted to investigate students' motivation, learning environment, learning behavior, learning attitude, teaching methods, English level in classroom English teaching. The questionnaire also includes students' personal basic information such as gender, age and graduation place. Students' engagement in classroom is reflected in the number of students' class engagement in teaching activities, including but not limited to students' answering teacher questions, duty report, role play, PPT presentation, classroom discussion, reading textbook, and class evaluation. Each question takes a median of 3.0 as a reference value. Questionnaire surveys take class as a unit for collective measurement. Teacher hands out the questionnaire in class and collects them on the spot. Of 1224 medical students' questionnaires, 35 were invalid questionnaires and questionnaire recovery rate was $99.97 \%$.

Statistical analysis methods. SPSS21.0 statistical software package is used for analysis, and general linear model is used to analyze the influence factors of students' engagement in the classroom teaching. Independent variables entered the model at a level of 0.05 , excluded standard was at 0.10 and testing standard was at a level of 0.05 .

\section{Results of the study}

The overall situation of students' class engagement in teaching activities. Statistics of 1189 effective questionnaires in classroom teaching of 6 class periods per week show that students participated in teaching activities up to 12 times a week, for a total of 3 persons, accounting for $0.3 \%$ of the total. While 141, 11.9\% of the students did not participate in any teaching activities within 6 periods. $70.6 \%$ of the students participated in classroom teaching activities for 3 times (including 3 times) or less, and the average number of all respondents participating in classroom teaching activities was $2.84 \pm 2.054$. The number of students participating in classroom teaching activities is seriously insufficient.

Factors affecting medical students' class engagement. There are many factors affecting medical students' class engagement. The author explores the relationship of motivation, environment, behavior, attitude, ways, English foundation, gender and students' source place of the medical students with the engagement in classroom activities.

\section{Motivation factors affecting medical students' engagement in classroom activities}

Table 1 shows that the average motivation of medical students to participate in classroom activities is $4.065 \pm 0.817$. Their engagement in teaching activities has a strong purpose. They think participating in teaching activities can improve their oral English and urge them to better learn the teaching material in each unit, have a good exercise of themselves, so that they can be more confident and get higher class performance marks.

Table 1 Students' participating motivation in classroom activities

\begin{tabular}{lccccc}
\hline Category & $\begin{array}{c}\text { Question } \\
\text { Item }\end{array}$ & $\begin{array}{c}\text { The Lowest } \\
\text { Point }\end{array}$ & $\begin{array}{c}\text { The Highest } \\
\text { Point }\end{array}$ & Mean & $\begin{array}{c}\text { The Standard } \\
\text { Deviation }\end{array}$ \\
\hline \multirow{3}{*}{ Motivation } & 1 & 1 & 5 & 4.05 & 0.805 \\
& 2 & 1 & 5 & 4.07 & 0.779 \\
& 3 & 2 & 5 & 4.09 & 0.761 \\
Total & 4 & 1 & 5 & 4.05 & 0.926 \\
\hline
\end{tabular}


Learning environment factors affecting the class engagement of medical students

The results of the engagement rate questionnaire survey of medical students in classroom related to their learning environment (family and class) show that the mean of students is $2.254 \pm 0.732$ (Table 2). Medical students believed that family democracy and familiarity with other students did not affect engagement in classroom teaching activities.

Table 2 Survey of learning environment on students' engagement in classroom activities

\begin{tabular}{|l|c|c|c|c|c|}
\hline \multicolumn{1}{c}{ Category } & $\begin{array}{c}\text { Question } \\
\text { Item }\end{array}$ & $\begin{array}{c}\text { The Lowest } \\
\text { Point }\end{array}$ & $\begin{array}{c}\text { The Highest } \\
\text { Point }\end{array}$ & Mean & $\begin{array}{c}\text { The Standard } \\
\text { Deviation }\end{array}$ \\
\hline \multirow{3}{*}{ Environment } & 5 & 1 & 5 & 2.98 & 0.564 \\
\cline { 2 - 6 } & 11 & 1 & 5 & 1.92 & 0.840 \\
\cline { 2 - 6 } & 14 & 2 & 5 & 2.12 & 0.866 \\
\cline { 2 - 6 } & 17 & 1 & 5 & 1.96 & 0.692 \\
\hline & 18 & 1 & 5 & 2.29 & 0.698 \\
\hline Total & 5 & 1.2 & 5 & 2.254 & 0.732 \\
\hline
\end{tabular}

Learning behavior factors affecting the engagement of medical students in classroom activities

According to the results of the survey on medical students' learning behaviors (Table 3), the average value is $4.185 \pm 0.857$. Students think playing mobile phones in class reduces their interest in participating in English learning. Moreover, they do not want to preview the learning content before class and it is hard to participate in classroom teaching activities.

Table 3 Study on students' learning behavior affecting engagement in classroom activities

\begin{tabular}{lccccc} 
Category & $\begin{array}{c}\text { Question } \\
\text { Item }\end{array}$ & $\begin{array}{c}\text { The Lowest } \\
\text { Point }\end{array}$ & $\begin{array}{c}\text { The Highest } \\
\text { Point }\end{array}$ & Mean & $\begin{array}{c}\text { The Standard } \\
\text { Deviation }\end{array}$ \\
\hline \multirow{2}{*}{ Behavior } & 9 & 1 & 5 & 4.21 & 0.899 \\
\hline Total & 21 & 1 & 5 & 4.16 & 0.814 \\
\hline
\end{tabular}

Learning attitude factors affecting the engagement of students in classroom activity

The result of the study attitude survey of medical students (Table 4) showed that the average value of students is $2.08 \pm 0.829$. Medical students are more confident and would not be afraid to be ridiculed, nor fear making mistakes in participating in classroom teaching activities. There are no professional reasons for not participating in classroom activities and they pay more attention to English class.

Table 4 Study on students' learning attitude affecting engagement in classroom activities

\begin{tabular}{|l|c|c|c|c|c|}
\hline \multicolumn{1}{c}{ Category } & $\begin{array}{c}\text { Question } \\
\text { Item }\end{array}$ & $\begin{array}{c}\text { The Lowest } \\
\text { Point }\end{array}$ & $\begin{array}{c}\text { The Highest } \\
\text { Point }\end{array}$ & Mean & $\begin{array}{c}\text { The Standard } \\
\text { Deviation }\end{array}$ \\
\hline \multirow{3}{*}{ Attitude } & 6 & 1 & 5 & 2.58 & 1.031 \\
\cline { 2 - 6 } & 12 & 1 & 5 & 2.06 & 0.918 \\
\cline { 2 - 6 } & 13 & 2 & 5 & 1.85 & 0.742 \\
\cline { 2 - 6 } & 16 & 1 & 5 & 2.22 & 0.831 \\
\hline & 19 & 1 & 5 & 1.89 & 0.709 \\
\hline & 20 & 1 & 5 & 1.90 & 0.744 \\
\hline Total & 6 & 1.2 & 5 & 2.08 & 0.829 \\
\hline
\end{tabular}

Teaching methods factors influencing the engagement of medical students in classroom activity

The results of the survey on teaching methods that influence the engagement of medical students in classroom teaching activities reflect that students generally believe that the teaching methods of 
middle school and university influence their engagement in classroom teaching activities (Table 5, average $4.285 \pm 0.902$ ). In high school, study is generally focused on college entrance examination, and students have fewer opportunities to participate in classroom activities, which have a certain impact on the formation of students' awareness of engagement in classroom teaching activities.

Table 5 Study on teaching methods affecting students' engagement in classroom activities

\begin{tabular}{lccccc}
\hline Category & $\begin{array}{c}\text { Question } \\
\text { Item }\end{array}$ & $\begin{array}{c}\text { The Lowest } \\
\text { Point }\end{array}$ & $\begin{array}{c}\text { The Highest } \\
\text { Point }\end{array}$ & Mean & $\begin{array}{c}\text { The Standard } \\
\text { Deviation }\end{array}$ \\
\hline \multirow{2}{*}{ Behavior } & 7 & 1 & 5 & 4.32 & 0.891 \\
& 8 & 1 & 5 & 4.25 & 0.912 \\
\hline Total & 4 & 1.25 & 5 & 4.285 & 0.902 \\
\hline
\end{tabular}

English level elements affecting the engagement of medical students in classroom activity

The study on English level elements affecting the engagement of medical students in classroom activity (Table 8, average $4.135 \pm 1.522$ ) shows that students generally believe that their English level, especially their speaking and listening, influences their enthusiasm for participating in English classroom learning.

Table 6 Behavioral investigation of students’ engagement in classroom activities

\begin{tabular}{lccccc}
\hline Category & $\begin{array}{c}\text { Question } \\
\text { Item }\end{array}$ & $\begin{array}{c}\text { The Lowest } \\
\text { Point }\end{array}$ & $\begin{array}{c}\text { The Highest } \\
\text { Point }\end{array}$ & Mean & $\begin{array}{c}\text { The Standard } \\
\text { Deviation }\end{array}$ \\
\hline \multirow{2}{*}{ Behavior } & 10 & 1 & 5 & 4.11 & 1.226 \\
& 15 & 1 & 5 & 4.16 & 1.818 \\
\hline Total & 4 & 1.25 & 5 & 4.135 & 1.522 \\
\hline
\end{tabular}

Gender impact on class engagement of medical students

Male and female students are different in the class engagement independent T-test analysis. The engagement of females in the classroom is higher than that of the males in class, and the difference is statistically significant $(\mathrm{P}(0.010) \leq 0.05$, male students are 445 while female 744$)$.

Students' graduation place on medical students' engagement in classroom activities

Students are from urban, town and rural areas according to students' source place. One-way anova shows that there is no significant difference in class engagement among urban, town and rural students in classroom activities $(\mathrm{P}(0.378) \geq 0.05$, students from urban are 293 , from town 246 , from rural 650).

\section{Discussion}

According to statistics and data analysis on the influential factors of medical students' class engagement, it is found that motivation, learning behavior, teaching methods, English level and gender of medical students have an impact on the engagement of medical students in classroom activities, while learning environment, learning attitude, graduation place have no significant effect. Therefore, teachers may improve teaching quality by improving students' motivation, learning behavior, teaching methods and grouping students so as to improve the engagement of medical students in classroom activities.

Strengthen students' motivation in learning and improve students' classroom engagement. Constructivism holds that "learning is a learner-centered learning under the guidance of a teacher, and it is necessary to emphasize the role of the learner as a cognitive subject and not to neglect the instructive role of the teacher." ${ }^{[6]}$ Students' learning process is a cognitive process based on teachers' guidance. The formation and development of student's subjective learning cannot be separated from teacher's education and guidance. In a sense, the leading role of teachers is to mobilize and give play to the main role of student learning as much as possible to stimulate students' motivation to learn and make students take the initiative to learn. Teaching is a process in which teachers and students communicate with each other. In this process, teachers should make every effort to 
improve students' interest in learning so that students can take the initiative to participate in the entire teaching activity process. This survey reflects students' strong motivation to improve their language skills and get the teacher's approval, teachers' timely praise to students, and higher daily performance marks. Teachers can give verbal commendations to students with high level of engagement in the classroom during their teaching. At the end of the semester, teachers can reward students with a higher mark of class performance to enhance students' sense of accomplishment and fulfillment in learning English so as to maintain the intrinsic motivation of English learning.

Enrich teaching methods, activate classroom teaching, improve students' classroom engagement. The questionnaire result shows that traditional high school education mode, which takes college entrance examination as baton, hinders the formation of students' class engagement awareness to a certain extent. Therefore, college English teaching should change traditional inculcating teaching mode and inspire students' interest in English learning through various teaching modes and arouse students' enthusiasm in class engagement. Therefore, how to stimulate students' interest in English learning is the key to improve students' engagement in English classroom. Teachers can use games, contests and other activities to add "seasoning" to English classes, and make English classes livelier. Turn English classes into a real paradise for students and stimulate students' enthusiasm for English learning. Make students feel deep love in English. Game itself needs the engagement of everyone. It can make boring contents lively and vivid so as to attract students' attention, arouse their interest in learning and improve their classroom engagement. Teachers can also use flipped classroom teaching mode or PBL teaching mode, or task-based teaching to create an educational context, stimulate students' initiative and improve students' engagement in learning ${ }^{[7]}$.Students explore with questions and improve students' interest in learning and their language skills by completing real tasks. Teacher changes from knowledge imparter and a major undertaker of teaching process to a counselor or mentor. Flipped classroom is a radical reform of traditional college English classroom teaching paradigm, putting classroom teaching into extra-curricular and placing extra-curricular tasks in-class ${ }^{[8]}$. In teaching, teachers can make groups, considering students' English level with both boys and girls, and girls are to give play to their language advantages to help each other and improve their English proficiency.

Scientifically use mobile phones, actively integrate into classroom activities. From medical students' questionnaire result, it is easy to find out that the use of mobile phones in medical students' classes has seriously affected their engagement in classroom activities. And medical students are also deeply aware that they are reluctant to preview learning contents and are hard to participate in teachers' classroom activities. Therefore, school needs to establish scientific classroom mobile phone management regulations. Medical students need to have correct mobile phone culture and use mobile phone rationally and scientifically. Make modern information technology serve learning and life instead of enslaving students. Let alone make phone a stumbling block to learning. And school should encourage medical students to learn, improve students' learning initiative, give play to their subjective initiative to learn. English learning requires the cooperation of both teachers and students. It is more important that students should take the initiative to construct learning, which requires medical students' initiative to learn.

\section{CONCLUSION}

Medical students' class engagement is directly related to the quality of their engagement in classroom activities and affecting their efficiency in acquiring and improving English language skills. Teachers need to change their educational concept and improve students' motivation in learning English. Change students' learning behavior and make flexible use of flipped teaching modes and PBL teaching so as to enhance students' interest in learning, enhance their confidence, encourage students and create conditions for them to actively use English in communication. Thereby students' English language ability can be improved by activating medical students' engagement in English classroom activities. 


\section{Acknowledgement}

The work was supported by Sichuan Provincial Foreign Language Literature Research Center Fund (No.: SCWYH17-05).

\section{References}

[1] Wang Chuanqi. Study on strategies to improve pupils' engagement in English classroom [J]. Journal of Chongqing Institute of Electronic Engineering, 2012,21 (01): 131-133.

[2] [4]Xu Jinglin, Tang Ying. Experiential teaching to enhance students' autonomous learning ---- A survey of English learning engagement in higher vocational colleges [J].Jiangsu Education, 2015 (28): 71-72.

[3] Xia Lili. A Practical Study on Enhancing Students' Engagement in English Learning from the Perspective of Global Learning [J].Jiangsu Education, 2016 (13): 23-26.

[5] He Rong. Influence of Flexible and Independent Classroom Activities on Class Engagement and Oral English Proficiency of Chinese College English Learners [D] .Guangdong University of Foreign Studies, 2014.

[6] Zhong Qiquan. Introduction to Curriculum and Teaching [M]. Shanghai: East China Normal University Press, 2008: 110-111.

[7] Zhang Wenfeng. Play the dominant position role of the students to improve English learning engagement [J] Talent, 2014 (33): $52+54$.

[8] Pan Xiaoquan. Micro-flipped classroom: an effective paradigm for enhancing engagement in college English learning [J]. Inner Mongolia Radio University, 2017 (04): 84-86. 